\title{
TECNOLOGIA E GÊNERO: REPENSANDO RELAÇÕES
}

\section{RESUMO}

Andrea Maila Voss Kominek amvkominek@gmail.com Universidade Tecnológica Federal do Paraná (UTFPR), Curitiba, Paraná, Brasil.

Ana Crhistina Vanali anacvanali@yahoo.com.br Universidade Federal do Paraná (UFPR), Curitiba, Paraná, Brasil.

\begin{abstract}
A relação entre tecnologia e gênero deve ser compreendida a partir de seu contexto histórico, cultural e social, assim como qualquer outro tipo de relação. Neste sentido, no presente trabalho será evidenciado as raízes de gênero na construção e utilização da tecnologia e analisar as contradições presentes no discurso de pretensa neutralidade de gênero. Busca-se apontar a necessidade de superar o paradigma cartesiano (eurocêntrico, branco e masculino) para assumir um sujeito além do teórico-universal, um sujeito corporificado $^{1}$, com especificidades e desafios particulares. A tradição cultural eurocêntrica e androcêntrica presente no meio universitário e científico permeia de forma subliminar o pensamento e os conceitos dos teóricos da ciência e da tecnologia. Assim, a pretensa neutralidade da tecnologia se orienta para relações monolíticas, herméticas e unilaterais, enquanto as perspectivas feministas desafiam esta racionalidade neutra e instrumental.
\end{abstract}

PALAVRAS-CHAVE: Gênero. Tecnologia. Cultura. Neutralidade Científica. 


\section{INTRODUÇÃO}

A partir de uma reflexão histórica de avanços da tecnologia doméstica², somada a conceitos da antropologia e da teoria de gênero, constata-se dois fatos que perpassam a atual sociedade tecnológica: 1- o fato de a tecnologia não ser normalmente pensada ou construída para mulheres, apesar de estas possuírem demandas e necessidades específicas; 2- o fato de independente de não ser pensada para elas, os avanços tecnológicos impactarem significativamente suas vidas.

Para tanto, parte-se da definição de tecnologia como construção social, cultural e temporal para denunciá-la, em uma sociedade desigual, como a sociedade capitalista ocidental, como instrumento para o empoderamento de uns em detrimento de outros (outras). Procura-se evidenciar tal proposição através de exemplos históricos de avanços tecnológicos, especialmente no espaço privado, que repercutiram de forma significativa na vida das mulheres. É urgente pensar a tecnologia a partir da perspectiva de gênero sob pena de, ao não fazê-lo, perpetuar as desigualdades sociais que assolam a sociedade, gerando tantas vezes preconceitos, revoltas e guerras.

\section{TECNOLOGIA: CONSTRUÇÃO SOCIAL, CULTURAL E TEMPORAL}

A tecnologia, como construção humana, é permeada de escolhas, valores, compreensões e percepções, mas também de seus silêncios e omissões. Uma sociedade desigual, excludente e opressora gera e reproduz valores, compreensões e percepções que sustentam e intensificam esta desigualdade. Esta constitui, exatamente, a situação da tecnologia na atual sociedade: um instrumento de manutenção e fortalecimento de desigualdades e injustiças.

O início do século XXI é cenário de transformações tecnológicas que trazem consigo mudanças em diversos setores da sociedade. Tecnologia e sociedade constituem construções inerentes à vivência humana e, portanto, estão intrinsecamente ligadas. Para Levy $(1997$, p. 5) "o mundo humano é desde sempre técnico". Destas mudanças emerge o assustador desafio contemporâneo: aprender a dominar a tecnologia sem ser por ela destruído ou deformado em sua humanidade.

Vive-se hoje o que poderíamos chamar de aceleração da tecnologia, através do aperfeiçoamento de equipamentos já existentes ou da inovação de sistemas anteriormente sequer imaginados. Nossa época, como aponta Dreifuss (1996), mostra exemplos das profundas mudanças em relação ao período anterior: $50 \%$ dos produtos que compunham nosso cotidiano no início dos anos 90, não existiam 25 anos antes, e hoje são corriqueiros; $50 \%$ dos objetos que formarão nosso universo dentro de 10 anos, ainda não foram inventados. Os avanços técnicos são inúmeros. A comunicação via satélite, a Internet presente em muitos lares, os microcomputadores portáteis, o intensivo uso de redes sociais através de celulares ultramodernos nas mãos da novíssima geração, além das consequentes transformações políticas, sociais e econômicas, constitui indícios de uma verdadeira mudança de paradigma tecnológico. 
Vivemos, por exemplo, uma reorganização do antigo conhecimento num conhecimento multitemático, interativo e sustentado pela nova tecnologia. Em cada lar abre-se através da janela virtual toda uma realidade desconhecida. O mundo está mais próximo e torna-se mais acessível a todos os setores e camadas sociais. Esta grande quantidade de novidades, no entanto, pode levar a um soterramento em informações e ao progressivo aumento das diversas formas de desigualdades sociais. É preciso desenvolver critérios para selecionar e descartar informações irrelevantes. É necessário um reordenamento de valores e prioridades, para que as novas realidades possam significar progresso para a toda a humanidade, pois como prova a história, o avanço tecnológico não garante o desenvolvimento na sociedade de modo geral e em seus diversos aspectos.

É neste mundo contemporâneo em transformação que o ser humano vê-se desafiado a preparar-se para ser mais do que o "indivíduo", ou o "trabalhador", para ser o "cidadão", capaz de reconhecer e defender sua cidadania. Um cidadão de múltiplas cores, culturas, idiomas e gêneros. Cidadania, num sentido amplo, que extrapola o conceito de cidadania em relação à pátria ou aos direitos constitucionais do cidadão, como o direito ao trabalho, à moradia ou à educação. Cidadania como valorização holística do "humano". Como um ser humano de plenos direitos e deveres, sim, mas também repleto de suas especificidades e idiossincrasias. Uma cidadania de iguais, mas não de idênticos e idênticas. Cidadania intrinsecamente ligada aos conceitos de autonomia, individualidade, reflexão crítica e participação ativa na sociedade.

Neste sentido e a respeito da educação técnica e tecnológica, Santos (1998) observa que, sob o pretexto de formar estudantes competitivos para o mercado de trabalho globalizado, o saber filosófico é preterido como desnecessário em função de saberes práticos reduzidos a processos de treinamento. A escola, ao fazer esta opção, deixa de ser o lugar de formação de verdadeiros cidadãos para tornar-se, como denuncia Santos (1998), um celeiro de "deficientes cívicos", desprovidos das noções clássicas como democracia, república, cidadania e individualidade.

Assim, para evitarmos uma sociedade de "deficientes cívicos", torna-se fundamental, como aponta Bastos (1998, p. 32), "registrar, sistematizar, compreender e utilizar o conceito e tecnologia, histórica e socialmente construído [....] numa dimensão que ultrapasse os limites das simples aplicações técnicas, como instrumento de inovação e transformação das atividades econômicas em benefício do homem, enquanto trabalhador e do país".

\section{TECNOLOGIA COMO EMPODERAMENTO DE UNS EM DETRIMENTO DE OUTROS (OUTRAS)}

Compreender a tecnologia como além da técnica, do desenvolvimento experimental e das pesquisas de laboratório, implica percebê-la como resultado dos processos históricos que a constituem, nos quais grupos de poder e influência ditam o ritmo e o tom. A tecnologia abrange as dimensões culturais e sociais humanas. Esta percepção da tecnologia como além da técnica e do instrumental, exige interpretações ampliadas, sensibilidade e respeito à diversidade, em todas as suas nuances, possibilidade de adaptação e organização, somadas à capacidade técnica. 
Assim, ao entender tecnologia como "o conjunto de meios ou atividades através dos quais o homem procura mudar ou manipular o seu ambiente" (FIGUEIREDO, 1989, p. 3), é preciso evidenciar que

[...] na mesma medida em que não se pode falar em tecnologia sem considerar as transformações sociais que estão ao mesmo tempo provocando e favorecendo seu desenvolvimento, também não se pode analisar a sociedade sem que se leve em consideração as transformações tecnológicas que estão ocorrendo dentro dela. (CARVALHO, 1997, p. 71)

Certeau (1995, p.10) afirma que "entre uma sociedade e seus modelos científicos, entre uma situação histórica e o instrumento intelectual que lhe é adequado, existe uma relação que constitui um sistema cultural" e Carvalho (1997, p. 71) que "sociedade é, antes de tudo, um produto das relações que se estabelecem entre os homens e que interferem na lógica de seu desenvolvimento, inclusive no desenvolvimento da tecnologia". Tomando estas afirmações como ponto de partida, é possível compreender o fato de que a sociedade capitalista, que vive, atualmente, a era da revolução digital, sofra aceleradas transformações sociais e culturais. Assim, dissolve-se as pretensões à possibilidade de neutralidade científica.

A aceleração do crescimento tecnológico evidenciou-se, mais enfaticamente, a partir do final dos anos 1960, através da utilização do código binário no desenvolvimento de computadores. Assim como da implementação, em 1961, do primeiro circuito integrado comercialmente viável e dos avanços tecnológicos deles decorrentes.

A sociedade contemporânea maravilhada e, ao mesmo tempo, perdida e assustada com este mundo novo, patrocinado pelos inúmeros e rápidos avanços tecnológicos, acabou por reificar a tecnologia e desvalorizar os aspectos sociais e humanos presentes no processo do progresso tecnológico. Neste contexto, os indivíduos tornam-se inseguros diante dos avanços que acarretam transformações de valores, padrões e modelos de comportamento sociais, porém hábitos e percepções de mundo dificilmente acompanham, na mesma velocidade, a aceleração das mudanças tecnológicas. Assim, "a atividade tecnológica é vista, por um lado, como um fator constitutivo da vida do homem em sociedade e, por outro, a tecnologia é sempre um elemento problemático na medida em que implica escolhas e decisões tanto para sua produção, como para sua difusão e seu consumo" (FIGUEIREDO, 1989, p.4). Para compreendê-la, portanto, é preciso aproximá-la do conceito de cultura.

Kluckhohn (1971) aponta que, para o antropólogo, a língua é, não apenas um produto, mas um comportamento cultural, e, portanto, não racional como qualquer outro aspecto da cultura. A influência da cultura na qual o indivíduo está inserido ocorre de forma constante, imperceptível e, na maioria da vezes, de forma subliminar. Não constitui, portanto, sua opção, sua escolha. A tecnologia, como construção social e temporal pode igualmente ser entendida com produto e comportamento cultural.

A cultura constitui elemento constante e afeta profundamente as escolhas e decisões da sociedade, o que abrange as escolhas a respeito da tecnologia. Cultura poderia ser entendida, metaforicamente, como o ar que se respira em 
determinado ambiente, de forma automática e normalmente imperceptível, porém sua qualidade e características influenciam diretamente o funcionamento do organismo.

Se, como afirma Kluckhohn (1971) sobre a linguagem, a língua pode revelar importantes características de uma cultura, chegando a considerá-la como "cultura pura", propondo ser a língua "o aroma essencial de cada cultura ou subcultura, uma fragrância" Kluckhohn (1971, p. 152), podemos entender a tecnologia como outra nota desta fragrância.

Neste sentido, a tecnologia, assim como a língua, reflete a situação social e cultural do falante. Pode-se inferir que assim como "o idioma é muito mais do que um veículo para troca" (Kluckhohn, 1971, p. 158), a tecnologia é muito mais do que instrumento e conhecimento técnicos, é também instrumento de auto expressão, localização social, cultural e emocional.

Para Geertz (1978), o conceito de cultura é uma construção semiótica, entendendo-a como um conjunto de mecanismos de controles (regras, padrões, modelos) que regulam e orientam o comportamento do ser humano na sociedade. Sobre a forma como concebe cultura, afirma também: "o homem é um animal amarrado a teias de significados que ele mesmo teceu, assumo a cultura como sendo essas teias e a sua análise" (GEERTZ, 1978, p. 15).

Podemos, neste momento, incorporar o conceito habermasiano de mundo da vida, como um complexo simbolicamente estruturado, composto pela personalidade do indivíduo, pela sociedade e suas regras, e pela cultura. Assim, cultura constitui um dos componentes do mundo da vida, constitui o pano de fundo para as relações sociais entre os sujeitos e a condição essencial para trocas comunicativas.

Através da lente formada pelos saberes tácitos e pré-reflexivos do mundo da vida, o indivíduo olha e compreende o mundo que o cerca. "A cultura é como uma lente através da qual o homem vê o mundo. Homens de culturas diferentes usam lentes diversas e, portanto, têm visões desencontradas das coisas" (LARAIA, 1993, p. 69). Neste sentido, Mccarthy (1995, p. 460) afirma que, sob a ótica do aspecto cultural, Habermas considera que "os desejos e sentimentos individuais não são essencialmente privados, mas ligados à linguagem e à cultura e, portanto essencialmente suscetíveis de interação, discussão e mudança".

Caberia neste momento questionar se tecnologia seria ou não componente do conceito de mundo da vida. Ora, compreendendo tecnologia como aqui proposto, como essencialmente humana, cultural e social, pode-se inferir que sim, que tecnologia compõe o mundo da vida habermasiano. A partir destes saberes do mundo da vida, incluindo nele a tecnologia, o ator social encara e interpreta o mundo. Neles encontram-se ocultas suposições e valores imperceptíveis a respeito das coisas, apreendidos de forma subliminar.

Em decorrência destes saberes então, pode-se inferir ser possível perceber no mundo apenas aquilo que nossa estrutura simbólica nos permita. Assim, se linguagem e tecnologia são comportamentos culturais, uma sociedade desigual, injusta, machista ou homofóbica, imprimirá em sua língua e em suas escolhas e prioridades tecnológicas estas mesmas características, ainda que o faça de modo oculto e automático. $\mathrm{O}$ espaço público, historicamente reservado aos homens viu crescer as conquistas tecnológicas, como as tecnologias da comunicação, do 
transporte e da informação. Necessidades masculinas para a "conquista do mundo" público e, até então, masculino.

Destinada ao espaço privado, no entanto, as vozes e necessidades femininas, foram por muito tempo silenciadas ou desconsideradas, como ainda ocorre em diversos setores do espaço público. Em recente artigo, Turk (2014) denuncia que "a tecnologia não é projetada para mulheres". Através de diversos exemplos, cita a promissora pesquisa sobre o implante de corações artificiais. Uma grande conquista tecnológica, porém, destinada a apenas uma parcela da população. Segundo a autora, "este dispositivo revolucionário atende à $86 \%$ dos homens, porém a apenas $20 \%$ das mulheres." (TURK, 2014, p.4) O motivo seria que o coração artificial possui dimensões fixas e a cavidade toráxica da mulher é menor. Investir no desenvolvimento paralelo de 2 modelos, o grande e o pequeno, implicaria muitos gastos e anos de estudos, por este motivo optou-se por seguir apenas um modelo: o maior!

Enquanto o espaço privado, doméstico, era entendido como um espaço destinado à "Rainha do Lar", este foi pouco afetado pelos primeiros avanços tecnológicos. Eletrodomésticos, por exemplo, passaram a ser uma prioridade apenas a partir do momento que os homens se viram "forçados", pelas circunstâncias históricas econômicas e sociais, a realizarem as "tarefas domésticas" ou a "ajudarem" suas esposas em suas realizações, especialmente quando as mulheres passaram a "trabalhar fora". Um exemplo desta situação pode ser observada, por exemplo, quando a panela elétrica de arroz eletrodoméstico de grande avanço tecnológico na época, foi introduzida no Japão, na década de 1950, quando

inicialmente se deparou com um grande problema em relação aos maridos, que na época assumiam posição superior em relação às mulheres e achavam que com este produto elas teriam tempo de sobra. O produto, em virtude disto, não teve boa aceitação. A publicidade passou então a ser direcionada aos maridos e não às esposas. O tempo livre feminino poderia ser usado para cuidar do marido." (ONO, 2006, p. 31)

No Brasil, os eletrodomésticos começaram a ser utilizados a partir de 1929, porém para que seu uso intensivo ocorresse, foi necessária muita publicidade (Abramovitz, 2006). O aspecto subliminar e oculto dos valores culturais subjacentes a esta realidade, no entanto, torna a manutenção destas características excludentes ainda mais fortes e perenes.

\section{MUDANÇAS TECNOLÓGICAS QUE IMPACTARAM A VIDA DAS MULHERES}

Considerando a atual sociedade capitalista, ocidental e contemporânea, parece fato a tecnologia constituir o motor propulsor e, ao mesmo tempo, o resultado de inúmeras modificações nos hábitos e práticas sociais deste início de século.

A lógica implacável do capitalismo, do lucro como objetivo maior, consequência da inicial busca do ser humano de controlar e dominar a natureza, e da histórica consolidação do modo de produção industrial, acabou por absorver a tecnologia em proveito próprio. Reforçado pelas inovações tecnológicas, passa 
a utilizá-la para o fortalecimento e expansão do próprio capitalismo, frequentemente desconsiderando o aspecto humano e as relações sociais da mesma. Tal absorção conduziu, gradualmente, a atual situação na qual as vantagens resultantes da tecnologia encontram-se restritas a um pequeno e privilegiado grupo, em detrimento da sociedade como um todo, pois, como aponta Figueiredo (1989, p. 13):

O avanço tecnológico, nas sociedades industriais contemporâneas, visa, teoricamente, à produção de mercadorias que, em termos imediatos, garantem o lucro e, a médio e longo prazos, asseguram a própria reprodução do sistema social. Tal fato não implica, porém, homogeneidade de criação de tecnologias e nem, tampouco, que as tecnologias deixem de provocar efeitos contraditórios nos contextos onde são produzidas e absorvidas.

A forma capitalista não é, certamente, a única forma, historicamente desenvolvida de organização social da humanidade e seria, portanto, ao menos em tese, passível de mudança e superação. O nível de desenvolvimento tecnológico alcançado pela humanidade, por outro lado, é, sem dúvida, irreversível.

Carvalho (1997) mostra como as inovações tecnológicas dos últimos anos vêm transformando, de forma acelerada, a vida humana. Tais inovações ocorrem, entretanto, de forma tão rápida, que não permitem, muitas vezes, por parte da sociedade, um real aproveitamento, ou assimilação delas, o que poderia, de outra forma, representar, de fato, melhorias e desenvolvimentos sociais.

Dentre as consequências destas transformações tecnológicas e sociais destaca-se, por exemplo, uma realidade que afeta diretamente o universo feminino: o surgimento de instituições para cumprir tarefas anteriormente destinadas à família, como creches para cuidar dos bebês, asilos para os idosos e doentes e escolas ampliando suas funções. Destaca ainda urbanização do cenário da vida social e a ampliação das discussões éticas, morais e jurídicas despertadas pelos avanços da biologia e da engenharia genética, especialmente nos aspectos de gênero e sexualidade.

As transformações tecnológicas afetam a vida da sociedade global como um todo, porém são os avanços tecnológicos destinados ao espaço doméstico (tecnologia doméstica) que muito contribuíram para a progressiva emancipação feminina. As mulheres, com o auxílio das tecnologias domésticas, menos sobrecarregadas de "suas" tarefas, passariam a ter, então, algum tempo privado. Uma vez que à mulher coube, historicamente, o espaço privado, seu tempo próprio nunca lhe foi concedido como privado, ao contrário, sempre fora destinado à família e ao cuidado do outro. Para a mulher, o tempo "no espaço privado", não corresponde a um tempo privado seu, ao contrário, constitui um tempo dedicado "ao outro", à família. O trabalho da mulher, ao dar-se no ambiente privado, não tem começo, nem fim. Trata-se de um trabalho em ciclo constante. Permanente.

Não é, portanto, um acaso que muitas das inovações tecnológicas destinadas ao espaço doméstico, ao cuidado e às ferramentas que permitiram a emancipação feminina, tenham sido promovidas por mulheres. Como coube às mulheres o peso do trabalho doméstico, compreensível que delas tenham vindo 
soluções e simplificações para este trabalho árduo e não reconhecido. Dois exemplos singelos e representativos são o desenvolvimento da fralda e do coador de café descartáveis.

A fralda descartável, lançada em 1951, desenvolvida por Marion Donovan, teve seu projeto inicialmente recusado pelos fabricantes que não viam necessidade de tal produto. Donovan passou a comercializá-lo pessoalmente, patenteou-o e vendeu-o por US\$ 1 milhão em valores da época, para a empresa Protcer \& Gamble, hoje líder de mercado. Amalie Mellita Bentz, em 1908, desenvolveu e lançou o filtro de papel descartável e tem até hoje seu nome associado a uma importante marca do setor.

Mas seguramente as duas invenções que maiores impactos tiveram na vida das mulheres foram: a pílula anticoncepcional e a mamadeira. Duas invenções que se tornaram um verdadeiro passaporte feminino para o espaço público.

A pílula anticoncepcional, lançada no mercado norte americano em 1960 foi o resultado de um projeto iniciado no início dos anos 1950 pela feminista Margaret Sanger e a milionária Katherine McCormick que tinham o objetivo de inventar uma pílula contra a gravidez que fosse fácil de usar, eficiente e barata. A pílula ocasionou uma reviravolta no conceito de sexualidade e para a mulher significou um enorme ganho de autonomia e liberdade para seu planejamento familiar, controle de seu próprio corpo e a nobre decisão de ser mãe, "se" e "quando" Ihe convier.

A mamadeira, por outro lado, permitiu à mulher que escolheu a maternidade não precisar abrir mão de ser também mulher plena, pois "defender o aleitamento materno pelo tempo que a criança demandar, significa privar a mulher de um tempo para si." (BADINTER, 2011, p. 133). A história da amamentação artificial, através do uso de recipientes possui registros já na Idade Média, porém o material utilizado, como couro, madeira e metal, aliados às péssimas condições de higiene levavam a um alto índice de mortalidade infantil até os 2 anos de idade. Duas conquistas tecnológicas permitiram sua melhor implementação: 1- o uso da cerâmica e do vidro e, em 1840, a descoberta da borracha galvanizada usada no bico; 2 - em 1864, a descoberta do processo de pasteurização, que permitia melhor controle da qualidade e conservação do leite.

Duas conquistas fundamentais para a vida da mulher moderna e contemporânea que tiveram vários opositores: as mulheres que utilizavam as pílulas teriam, supostamente, "caráter duvidoso", enquanto as mães que utilizavam as mamadeiras eram "péssimas mães", duramente criticadas por maridos, sogras e pediatras.

Apesar das advertências dos médicos contra a mamadeira e em defesa do aleitamento natural até imediatamente após a Segunda Guerra Mundial, muitas mães se fizeram de surdas. A mamadeira, que triunfa depois da guerra, será considerada uma solução de compromisso visando conciliar os interesses pessoais da mulher e os da mãe. A mamadeira é a possibilidade de ir e vir e a de ser substituída junto ao bebê. É, pois, a liberdade restituída àquelas que desejam levar simultaneamente uma vida de mãe e mulher (BADINTER, 2011, p. 134). 
Muitas outras são as mulheres cientistas e inventoras na história da ciência e da tecnologia, porém no presente trabalho não se visou fazer um recorrido histórico, mas sim evidenciar conquistas de grande impacto na vida da mulher e seus efeitos.

\section{CONSIDERAÇÕES FINAIS}

Buscou-se neste trabalho denunciar a realidade contemporânea sobre o aspecto de seu desenvolvimento tecnológico, no qual, apesar de a tecnologia não ser tradicionalmente pensada ou construída por e para mulheres, seus avanços impactam significativamente suas vidas, especialmente no espaço doméstico.

Assim, pensar a tecnologia a partir de uma perspectiva de gênero constitui uma necessidade que não pode mais ser adiada na atual conjuntura de desenvolvimento social, com vistas a um gradual desaparecimento das desigualdades e para a conquista de uma sociedade efetivamente justa.

Se, por um lado, não se pode negar que o progresso tecnológico traga amplas possibilidades de facilitar a vida humana. Por outro lado, não se pode esquecer que a maioria dos seres humanos do planeta não tem acesso e não vivenciam estas facilidades trazidas pela tecnologia. Neste sentido, uma das principais marcas do sistema capitalista e patriarcal é a acumulação da riqueza e acesso aos avanços tecnológicos por uns, e a pobreza, exclusão e inacessibilidade aos avanços por outros e outras.

Sob estas condições, configura-se uma nova divisão social: os que detém e os que não detém informação, os que influenciam e as que não influenciam nas decisões tecnológicas. Existem aqueles que usufruem do progresso tecnológico e aquelas que se encontram impedidas de fazê-lo. Dentre aqueles que aproveitam as vantagens da tecnologia é compreensível, talvez, que ocorra um certo encantamento com o maravilhoso mundo novo da tecnologia. A este respeito, Carvalho (1997, p. 71) comenta:

O desenvolvimento tecnológico é visto pelos que dele participam como um fenômeno que por si só é positivo, pois significa o progresso e este é sempre intrinsecamente bom. Na sociedade ocidental moderna, progresso quer dizer a utilização de tecnologias cada vez mais avançadas que supostamente melhorariam a qualidade de vida de todos.

Dentre aqueles e aquelas que não disfrutam das vantagens da tecnologia, no entanto, verifica-se também uma certa reificação da tecnologia, entendida, aqui, como alienação que confere vida e independência à tecnologia, como uma hipervalorização e crença no aspecto positivo e emancipador da tecnologia. Fato que ocorre, no entanto, de forma imperceptível ao próprio individuo. Tal situação decorre do forte trabalho de propaganda costumeiramente feito sobre a tecnologia, a ponto de fazer com que o indivíduo que a ela não têm acesso, ainda assim acredite em seu poder emancipador e de progresso da sociedade de modo geral, sendo ele (ou ela) apenas vítima "circunstancial" de sua ausência. Trata-se de uma questão de fé e não de algo racional ou empiricamente constatado.

Neste sentido, Figueiredo (1989) aponta para o fato de a tecnologia ser marcada pelos interesses dominantes de cada contexto sócio-histórico específico 
e, ao mesmo tempo, apresentar-se como a serviço de todos. Afirma ainda ser este seu caráter ideológico e responsável por reduzir o conteúdo emancipatório e libertador da tecnologia. Disto decorre a fundamental importância de denunciar seu aspecto ideológico e a mentirosa suposta neutralidade política, econômica ou de gênero. Assim, como enfatiza Figueiredo (1989, p. 20):

Ao destacar-se, então, a dimensão política da tecnologia, sublinham-se os seguintes aspectos: a direção do avanço tecnológico depende, em grande parte, dos interesses que prevaleçam sobre outros que se Ihes oponham a cada momento; a tecnologia não é, assim, mecanicamente derivada quer de pressões econômicas, quer de condicionantes científicos; o campo de decisões que a tecnologia comporta não é o do exercício indeterminado da vontade. 


\title{
TECHNOLOGY AND GENDER: RETHINKING RELATIONSHIPS
}

\begin{abstract}
The relationship between technology and gender must be understood from its historical, cultural and social context, as well as any other type of relationship. In this sense, in the present work will be evidenced the roots of gender in the construction and use of technology and analyze the contradictions present in the discourse of alleged gender neutrality. It seeks to point out the need to overcome the Cartesian paradigm (Eurocentric, white and masculine) to assume a subject beyond the theoretical-universal, a person embodied, with particularities and particular challenges. The Eurocentric and andrcentric cultural tradition present in the university and scientific milieu subliminally permeates the thinking and concepts of science and technology theorists. Thus, the alleged neutrality of technology is oriented toward monolithic, hermetic and unilateral relations, while feminist perspectives challenge this neutral and instrumental rationality.
\end{abstract}

KEYWORDS: Gender. Technology. Culture. Scientific Neutrality. 


\begin{abstract}
NOTAS
1 Optou-se nesta pesquisa por utilizar as expressão "corporificado" na intenção de afastar-se da tradição cartesiana na qual define-se a essência do sujeito de forma incorpórea, uma vez que a prova de sua existência seria o pensar. Aproxima-se, ao contrário, de considerar as especificidades de cada corpo no momento da análise teórica. Ao utilizar termos supostamente "neutros", por exemplo, como nos casos em que se utiliza o substantivo masculino como "genérico", desconsidera-se assim, as especificidades do sujeito "feminino", como se observará ao longo deste artigo.

2 Tecnologia doméstica entendida aqui como aquela presente nos lares, especialmente sob a forma de eletrodomésticos e de avanços tecnológicos que facilitam as tarefas domésticas: desenvolvimento de materiais como a borracha, a luz elétrica, os tecidos com alta tecnologia, dentre outros.
\end{abstract}

\title{
REFERÊNCIAS
}

ABRAMOVITZ, José. Eletrodomésticos: origens, história e design no Brasil. São Paulo: Fraiha, 2006.

BADINTER, Elisabeth. O conflito: a mulher e a mãe. Rio de Janeiro: Record, 2011.

BASTOS, João Augusto de S. L. (org). Tecnologia e interação. Publicação do Programa de Pós- Graduação em tecnologia PPGTE/CEFET-PR. Curitiba: CEFET-PR, 1998.

CARVALHO, Marília Gomes. Tecnologia, desenvolvimento social e educação tecnológica. In: Revista Educação \& Tecnologia, Curitiba, Ano 1, n.1, 1997, p-7087 , jul.

CERTEAU, Michel de. A cultura no plural. Campinas: Papirus, Coleção Travessia do Século, 1995.

DREIFUSS, René Armand. A época das perplexidades: mundialização, globalização e planetarização: os novos desafios. Petrópolis: Vozes, 1996.

FIGUEIREDO, Vilma. Produção social da tecnologia. São Paulo: EPU, 1989.

GEERTZ, Clifford. A interpretação das culturas. Rio de Janeiro: Zahar, 1978.

KLUCKHOHN, Clyde. Antropologia, um espelho para o homem. Belo Horizonte: Itatiaia, 1971. 
LARAIA, Roque de Barros. Cultura: um conceito antropológico. 8a edição. Rio de Janeiro: Zahar, 1993.

LÉVY, Piérre. O inexistente impacto da tecnologia. in: Folha de S. Paulo, 17 de agosto, caderno 3 (mais!), 1997, p. 5.

McCARTHY, Thomas. La teoria critica de Jurgen Habermas. 3 ed. Madrid: Editorial Tecnos, S.A, 1995.

ONO, Maristela Mitsuko. Design e cultura: sintonia essencial. Curitiba: EDUTFPR, 2006.

SANTOS, Milton. Entrevista a Caros Amigos, no 17. São Paulo, agosto de 1998. Disponível em http://www.carosamigos.com.br/index.php/grandesentrevistas/6047-entrevista-explosiva-com-milton-santos. Acesso em 17/10/ 2016.

TURK, Victoria. A tecnologia não foi projetada para mulheres. 2014 Disponível em http://motherboard.vice.com/pt_br/read/a-tecnologia-nao-e-projetada-paramulheres. Acesso em 13/11/ 2016.

Recebido: 30 de março de 2016.

Aprovado: 14 de abril de 2016.

Como citar:

KOMINEK, A. M. V.; VANALI, Ana Crhistina. Tecnologia e gênero: repensando relações. Cad. Gên. Tecnol., Curitiba, v. 9, n. 33, p. 37-49, jan./jun. 2016.

Correspondência:

Andrea Maila Voss Kominek

Av. Sete de Setembro, 3165. CEP 80230-901. Curitiba, Paraná.

Direito autoral: Este artigo está licenciado sob os termos da Licença Creative Commons Atribuição 4.0 Internacional.

\section{(c) (1)}

